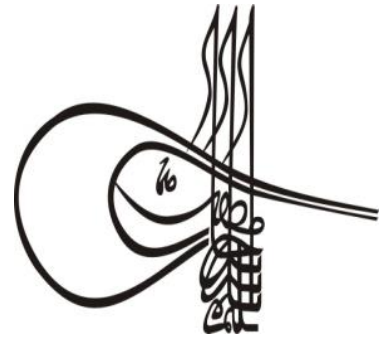

Received/Geliş: 30.08.2019

\section{Turkish Studies Historical Analysis}

Volume 14 Issue 3, 2019, p. 497-510

DOI: 10.29228/TurkishStudies.36953

ISSN: 2667-5552

Skopje/MACEDONIA-Ankara/TURKEY

Research Article / Araştırma Makalesi

Article Info/Makale Bilgisi

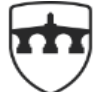

INTERNATIONAL BALKAN UNIVERSITY

EXCELLENCE FOR THE FUTURE IBU.EDU.MK

\title{
DARÜLACEZE KEŞF-İ SÂNİ DEFTERİ
}

\author{
Kadir EKINCCI*
}

\section{öz}

Temeli 1892 yılinda atılan ve 1896 yılında hizmete alınan Darülaceze binaları, gerek işlevi gerek inşa süreçleri bakımından son dönem Osmanlı mimarlığında önemli bir yer tutar. Sultan II. Abdülhamid'in teşvik ve girişimleriyle kurulan Darülaceze, muhtaçların ihtiyaçlarını karşılama işlevinin yanında, yetimhane, bakımevi, hastane, meslek kazandırma merkezi gibi işlevlere de sahipti. Bu işlevlerin yanında Darülaceze sakinlerinin ibadetlerini yerine getirmeleri için cami, kilise gibi ibadethanelere de yapı kompleksinde yer verilmiştir. Darülaceze inşaatı sırasında, yapı kompleksinin büyüklügü ve farklı işlevlere sahip birçok yapının bir arada bulunması nedeniyle maddi kaynak ve yapı malzemesi temini, çalışmanın sağlıklı bir şekilde yürümesi adına büyük önem taşımaktaydı. Bu nedenle yapı kompleksinin inşaatına başlanmadan önce bir komisyon kurularak kompleksin kapasitesi belirlenmiş ve mimari projelerin hazırlanmasının ardından keşif çalışmaları yapılarak, yapının yaklaşık maliyeti belirlenmiştir. Bununla birlikte inşa sürecinde bir takım problemlerle karşılaşılmış ve maliyetler tahmin edilenin dişında gelişmiştir. Bu noktada ise keşf-i sâni defteri kavramı karşımıza çıkmaktadır. Darülaceze binalarının inşaatlarının tamamlanmasının ardından hazırlanan keşf-i sâni defteri, inşaat sürecinde gerçekleştirilen imalatın miktar ve maliyetlerinin hesaplandığı defterdir.

Bu çalışmada ilk olarak Darülaceze'nin kuruluşu ile kompleksteki yapıların işlevlerine değinilecektir. Sonrasında ise Osmanlı'da maliyet tahmin yöntemlerinden bahsedilerek Darülaceze keșf-i sani defteri, yapının inşa edildiği döneme ait diğer belgelerle desteklenerek tanitılmaya çalışılacaktır.

Anahtar Kelimeler: 19. yy Osmanlı Mimarlığı, Maliyet Tahmin Yöntemleri, Geleneksel Yapım Teknikleri, Geleneksel Yapı Malzemeleri. 


\title{
KEŞF-İ SÂNİ (SECOND COST ESTIMATION) BOOK OF DARÜLACEZE
}

\begin{abstract}
The Darülaceze buildings, whose foundations were laid in 1892 and inaugurated in 1896, take an important place in the late Ottoman architecture in terms of its function and construction process. The complex founded with encouragement and initiatives of Sultan Abdülhamid II, had functions such as orphanage, nursing home, hospital and vocational training center in addition to meeting the needs of poor people. In addition to these functions, places of worship such as mosque and church have been included in the complex for residents of Darülaceze to perfom their prayers. During the construction of Darülaceze, supply of pecuniary resources and building materials was of great importance in order to carry out the work succesfully, due to the size of the complex and the functions of the buildings in it. Therefore, before commencing the construction process, a commission was established to determine the capacity of the complex and cost estimation works were completed after the architectural projects were prepared. However, a number of problems were encountered during the construction process and costs developed beyond the estimations. At this point, the concept of Keşf-i Sâni (second cost estimation) book appears. The second cost estimation book prepared after the completion of the constructions, is the book which the quantities and costs of the works realized during the construction process were calculated.

In this paper, establishment of Darülaceze and the functions of the buildings in the complex will be firstly mentioned. Afterwards, cost estimation methods in Ottoman Empire will be discussed and Keşf-i Sâni (second cost estimation) Book of Darülaceze will be presented with other documents from the same period in which the complex was built.
\end{abstract}

\section{STRUCTURED ABSTRACT}

Following the defeat in Russo-Turkish War of 1877-1878, Ottoman Empire suffered a great loss of land and during this period, Istanbul had received huge groups of refugees both from the Balkans and the Caucasus. As a result of these migrations, the social balance in the capital was interrupted; many problems such as sheltering, meeting the needs of orphans and homeless poeple have emerged. At that point, Ottoman Council of Ministers agreed on the construction of a "Darülaceze" in Istanbul at its meeting dated 7 September 1886.

The article in Servet-i Fünun magazine dated 27 July 1893, is an interesting source to introduce the Darülaceze building complex. According to the site plan published in the magazine, the complex consists two sections; Christian and Muslim, with four buildings, a bath and a hospital each, as well as mosque and church. In addition to these, there were other buildings such as kitchen, warehouse and workshop (as vocational school) for common use. The entrance to the building complex was made through the administrative building. 
Before commencing the construction works, a commission was established under the presidency of Sultan Abdülhamid II, the capacity of the building complex and the approximate construction cost were determined. Accordingly, the capacity of the building complex was determined as 1500 and the approximate construction cost was calculated as 45,000 liras (4.5 million kuruş). In the notification dated 25 June 1892, it was stated that the drawings made by the royal architect Yanko Efendi were approved by the Sultan and the building complex would be built on the ridges of Kağithane. The tender by dutch auction which was realized on 11 September 1892 was first won by Ohannes Kalfa and then Vasilaki Kalfa of the royal shipyards. The site was delivered to the contractor on 18 October 1892 and the foundations of the building were started to be laid on 1 November 1892 .

Cost estimation was called as kârnâme in Ottoman period and done in two different methods; satrançcini (graph paper) and keşif (estimation) were used for preparation of kârnâme.

Keşif is the estimation method which is still used today. According to this method, quantity survey of the building is prepared and calculation is made including labor costs in order to get the apporximate cost. This estimation which is done before starting the construction is called kesff-i evvel (first estimation). But the book which was examined in this paper is an example of keşf-i sani (second estimation). Although it is defined as an additional estimation calculation for the works which were not added or could not be added to the first one, keşf-i sani is defined as follows in the Keşf-i Sani Book of Darülaceze: "This is the second cost estimation book that consist real expenditures, quantities and types of the works and measurements realized for Darülaceze buildings in the guidance of first cost estimation book and the application methods of the works done." In the light of this information, it can be said that the contents of kessf-i sani books may vary according to the building and the period.

One of the publication that gives important information about construction process of Darülaceze is Servet-i Fünun magazine as it was mentioned above. According to the observations and informations obtained during a visit to the construction site for the issue of the magazine dated 27 July 1893, walls of the buildings were $1.5 \mathrm{~m}$ high from the ground and 1200 workers were employed in the construction activities. 800 of those workers were working in the construction site, 100 were in granite quarries of Bandırma Yapıcı Köyü, 60 were in Kurbağalıdere quarry, 50 were in Sütlüce, 50 were in Arnavutköy quarries, 20 were in Makriköy (Bakırköy) quarries. Besides, 120 workers were working in lump-sum system for the construction. According to the information given by Servet-i Fünun magazine, it is seen that workers were divided into small groups for working in more than one quarry and the reason is also given in the same article of magazine.

In the same years with Darülaceze, the construction of Galata Quay was also started and it continued even after the completion of Darülaceze construction. Serious problems were encountered during the construction of Galata Quay for supplying the necessary amount of stones. Thus, the contractor company of Galata Quay construction, opened new quarries in addition to rent all of the quarries in Istanbul. 
This situation had also effected construction process of Darülaceze and importing stones from Trieste and Marseille came into agenda, instead of the stones mentioned in kontrato (construction specifications) and first estimation. As a result of mechanical tests and price comparisons, the tender commission evaluated that they are suitable to use but only in limited amounts because of their prices.

As can be seen from the above information, there is a need for a second estimation due to unforeseen developments in the construction process. Second cost estimation book of Darülaceze is a book in which all works performed during the construction are classified by units of each building and actual construction costs are calculated with quantity survey including material and labor prices .

The first article of the book contains the calculation of preparations for groundbraking works by leveling the ground. The second article is the cost of foundation construction. The articles in the book are divided into sub-articles for each building of the complex. As it is understood from the article that contains the calculation of foundation construction, foundations were built with Kağithane stone and a mortar prepared with lime and river sand. According to the information given in Servet-i Fünun magazie, the stone called as Kağıthane stone in the book, must be the Sütlüce stone mentioned in the magazine.

The third article of the book gives the cost calculation for main walls of the buildings and also a detailed explanation about how the walls should be built. The detailed definitions given in the book also allow us to learn meanings of the names and details of the construction techniques that are no longer used. This also applies to material names and mortar contents in the book. Another advantage provided by the detailed definitions in the book is that as the technique is simply explained, making detailed restitution drawings becomes possible.

Keşf-i sâni (second estimation) books prepared for Darülaceze and other buildings are the documents that can make significant contributions especially in use of materials, construction details and building terminology in order to understand and correctly evaluate the architectural practices of Ottoman period. Besides, it is considered that it will be useful to include kessf-i sani books in the research processes, considering that they can contribute necessary information about restitution and materials for conservation and restoration works.

Keywords: 19th Century Ottoman Architecture, Cost Estimation Methods, Traditional Building Techniques, Traditional Building Materials.

\section{Darülaceze'nin Kuruluşu}

Adının günümüz Türkçesindeki karş1lığ "güçsüzler yurdu" olan Darülaceze'nin kuruluşu ilk olarak 1886 yılında gündeme gelmiştir. Osmanlı Devleti 93 Harbi'nde (1877-1878) aldığ yenilginin ardından büyük bir toprak kaybı yaşamış ve bu dönemde İstanbul, hem Balkanlardan hem de Kafkaslardan büyük göçler almıştır. Bu göçler sonucunda kentteki sosyal denge bozulmuş; kimsesiz, muhtaç, evsiz birçok kadın, erkek ve çocuğun barınma, beslenme ihtiyaçlarının karşılanması gibi büyük sorunlar baş göstermiştir. Bu gelişmelerin ardından Meclis-i Mahsus-u Vükela, 7 Eylül 1886 
tarihli toplantısında İstanbul'da bir Darülaceze yapımı konusunda uzlaşmıştır (Özen,2001). Yapım çalışmalarının başlamasıyla ilgili en önemli adım ise Sultan II. Abdülhamid'in 7 Nisan 1890 tarihli iradesiyle atılmıştır (Darülaceze, 1906). Sultan II. Abdülhamid, bu iradesiyle dilenmekte olan kimsesiz çocukları, muhtaç durumdaki kadın ve erkekleri hem dilenmekten kurtarmak, hem de eğitim ve bakımlarını üstlenmek üzere bir yer ayrılmasını, bu konuda alınacak tedbirlerin ve yapılacak projelerin en kısa sürede kendisine iletilmesini emretmiştir (Özen, 2001).

İnşaat çalışmalarına başlanmadan önce, Sultan II. Abdülhamid başkanlığında bir komisyon kurularak, yapı kompleksinin kapasitesi belirlenmiş ve yaklaşık yapım maliyeti tespiti yapılmıştır. Buna göre yapı kompleksinin kapasitesi 1500 olarak kararlaştııılarak yaklaşık yapım maliyeti 45000 lira (4.5 milyon kuruş) olarak hesaplanmıştır (Özen, 2001). 25 Haziran 1892 tarihli tebligatta ise yapının Saray-1 Hümayun mimarı Yanko Efendi tarafından yapılan çizimlerin padişah tarafından onaylandığ ve yapı kompleksinin Kağıthane sırtlarına inşa edileceği belirtilmiştir (Darülaceze, 1906). İnşaatın açık eksiltme yoluyla yapılan ihalesi 11 Eylül 1892 tarihinde önce Ohannes Kalfa'ya sonra Tersane-i Amire kalfası Vasilaki Kalfa'ya kalmıştır. 18 Ekim 1892 tarihinde yer teslimi yapılarak, 1 Kasım 1892 tarihinde yapının temelleri atılmaya başlanmıştır (Darülaceze, 1906).

Darülaceze'nin muhtaçların barınma ve beslenme ihtiyaçlarını karşılamanın yanında meslek kazandırma gibi bir işlevi de vardı. Bu nedenle terzihane, kundura işliği, halı işliği, dokuma işliği, marangozhane, fotoğraf işliği, demir işliği vb. mekânlar da kompleksteki yapılarda yer alıyordu. Kompleksteki tüm yapıları tanıtmak adına 27 Temmuz 1893 tarihli Servet-i Fünun dergisindeki makale ilginç bir kaynak teşkil etmektedir. Dergide verilen vaziyet planına göre kompleks Hristiyan ve Müslüman olmak üzere iki bölümden olușmakta, bu bölümlere ait dörder bina, cami ve kilise ile birlikte birer hamam ve hastane de bulunmaktaydı. Bununlarla birlikte komplekste ortak kullanım için mutfak, depo, işlik gibi yapılar da yer alıyordu. Yapı kompleksine giriş ise idari binadan geçilerek yapılmaktaydı (Şekil 1) (Servet-i Fünun, 1893).

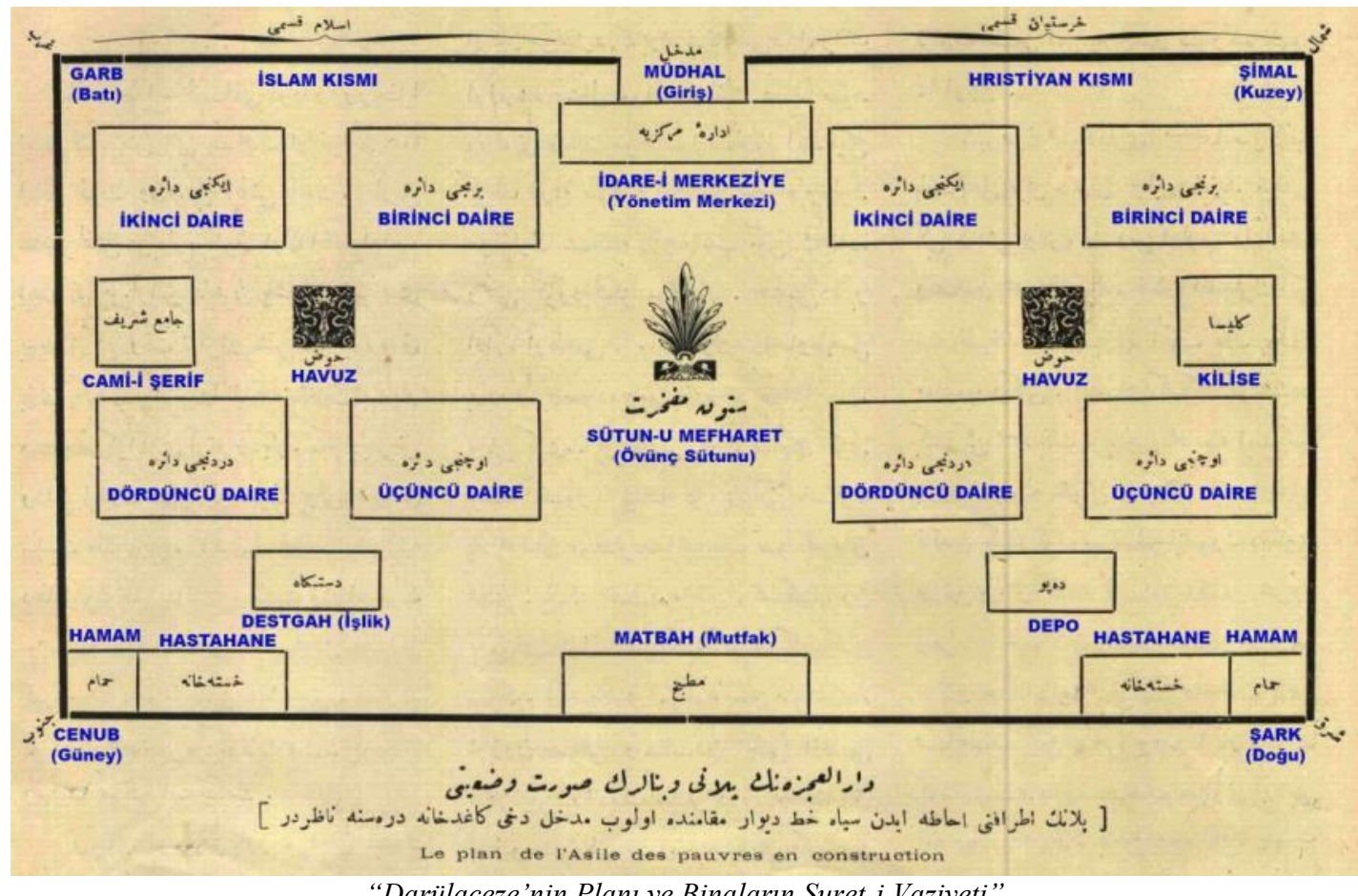

"Darülaceze 'nin Plant ve Binaların Suret-i Vaziyeti"

(Planın etrafinı ihata eden siyah hat, duvar makamında olup medhal dahi Kağıthane Deresi 'ne nazırdır)

Şekil 1: Darülaceze Vaziyet Planı (Servet-i Fünun, 1893) 


\section{Osmanlı Döneminde Maliyet Tahmin Yöntemleri}

Osmanlı döneminde inşaat maliyet tahmini kârnâme olarak da anılmaktaydı (Ünsal, 1963; akt. Yılmaz, 2012). Karname hazırlanması amacıyla satrançcini (kareli kağıt) ve keşif olmak üzere iki farklı yöntem kullanılmaktaydı (Yılmaz,2012).

\section{Keșif yöntemi}

Maliyet tahimini için kullanılan yöntemlerden ilki, günümüzde de kullanılmaya devam eden keşif yöntemidir. Bu yönteme göre yapıların metrajları çıkarılmakta ve işçilik maliyetleriyle birlikte hesaplar yapılarak yaklaşık maliyete ulaşılmaktadır. İnşaata başlanmadan yapılan bu keşfe "keşf-i evvel" denilmektedir. Çalışmada incelenen defterin de bir örneğini teşkil ettiği "keşf-i sani" ise "ilk keşfe eklenemeyen ya da yeni ilave edilen işler için yapılan ek keşif" olarak tanımlansa da (Hızlı, 1991 akt. Yılmaz,2012), Darülaceze keşf-i sani defterinin başlangıcında defter şu şekilde tanımlanmaktadır (Şekil 2):

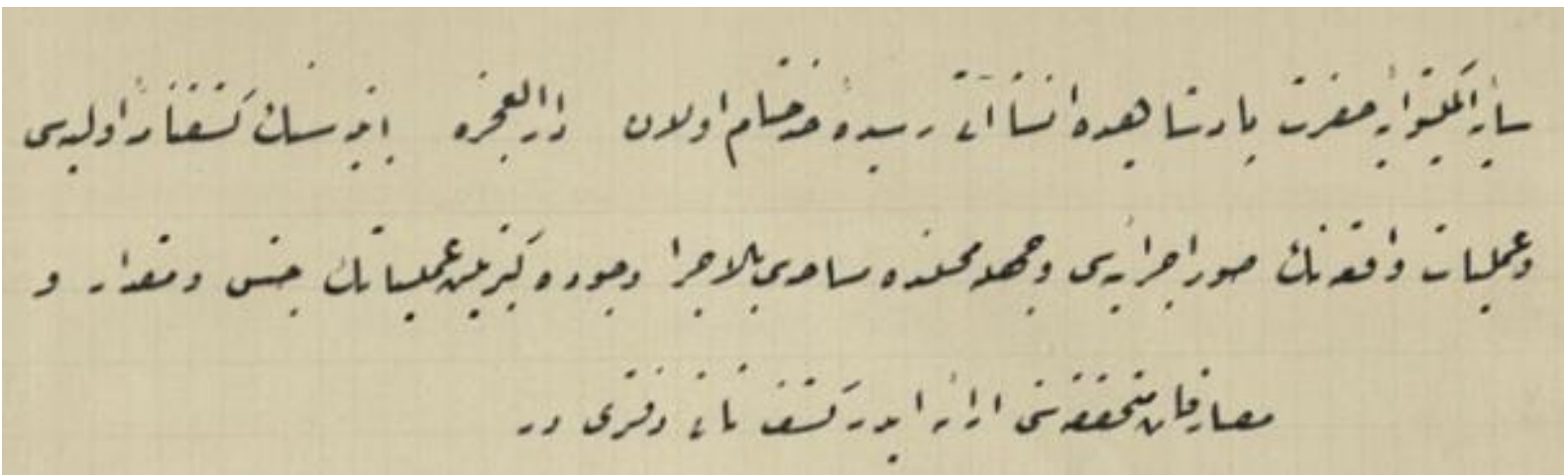

Şekil 2: Darülaceze Keşf-i Sâni Defterinin İlk Satırları (BOA-1)

“... Darülaceze ebniyesinin keşifname-i evveliyesi ve ameliyat-1 vakıanın suver-i icraiyesi vechiyle mahallinde mesahası bi'l icra vücuda getirilen ameliyatın cins ve mikdar ve mesarifat-ı mütehakikasını irae eder keşf-i sâni defteridir."

Günümüz Türkçesiyle: “... Darülaceze binalarının birinci keşfi ve yapılan işin uygulama biçimleri vesilesiyle yerinde yapılan ölçümler ve yapılan işlerin gerçek cins, miktar ve masraflarını içeren ikinci keşif defteridir."

$\mathrm{Bu}$ bilgiler 1şı̆̆ında keşf-i sani defterlerinin içeriklerinin yapıya ve döneme göre değişiklik gösterebileceği söylenebilir.

\section{Satrançcini yöntemi}

Bu yöntemle ilgili bilgileri İbrahim Yılmaz doktora tezinde farklı kaynaklardan derleyerek aktarmaktadır. Behçet Ünsal'dan aktaran Yılmaz, bu yönteme Çorum Abdal Ata Türbesi'nini maliyet tahmin sürecini örnek göstermekte ve Gülru Necipoğlu tarafından yayınlanan çizimlerle yöntemi şöyle açıklamaktadır:

“Mimar tarafından Şekil 3'te görüldüğü gibi, türbe planının üç alternatifi hazırlanmıştır. Bu planlar maliyet tahmini için (karname) yapılmış etüde ait olmaktadır. Şekil 3'te ise, ilk alternatif için hazırlanmış olan satrançcini oturumu sunulmuştur. Şekil 2'de sol üst köşedeki plan ilk tekliftir; bir köşesinde 'tulı ve arzı on arşın' diye yazılıdır. Yukarı başında ise, 50 bin akçe olur denilmektedir. Sağ üst köşede bulunan ikinci plan, ilk şekle ilave edilen bir modül ile, iki gözlü olarak düşünülmüştür. Üzerinde "bu iki kubbe olur, tahminen 78 bin akçe olur" diye yazılıdır. İlave edilen mahal de makbere binası gibi, içten içe ölçüsü 10x10 arşındır. Sağ alt köşedeki üçüncü plan, bu plana ikinci plan ölçüsü kadar bir modül daha ilave edilerek genişletilmiştir. Bu planlarda dikkat edilecek önemli 
nokta mahallerin hep 10x10 arşın kare birim (modül) ölçüsü ile tertiplenmiş olmasıdır. $\mathrm{Bu}$ son şeklin tahmini maliyetinin 120 bin akçe olacağı plan üzerinde yazılıdır. Bir köşesinde de 'bunu talep ederler dört kubbe olur' diye kaydedilmiştir." (Ünsal, 1963; akt. Y1lmaz,2012)

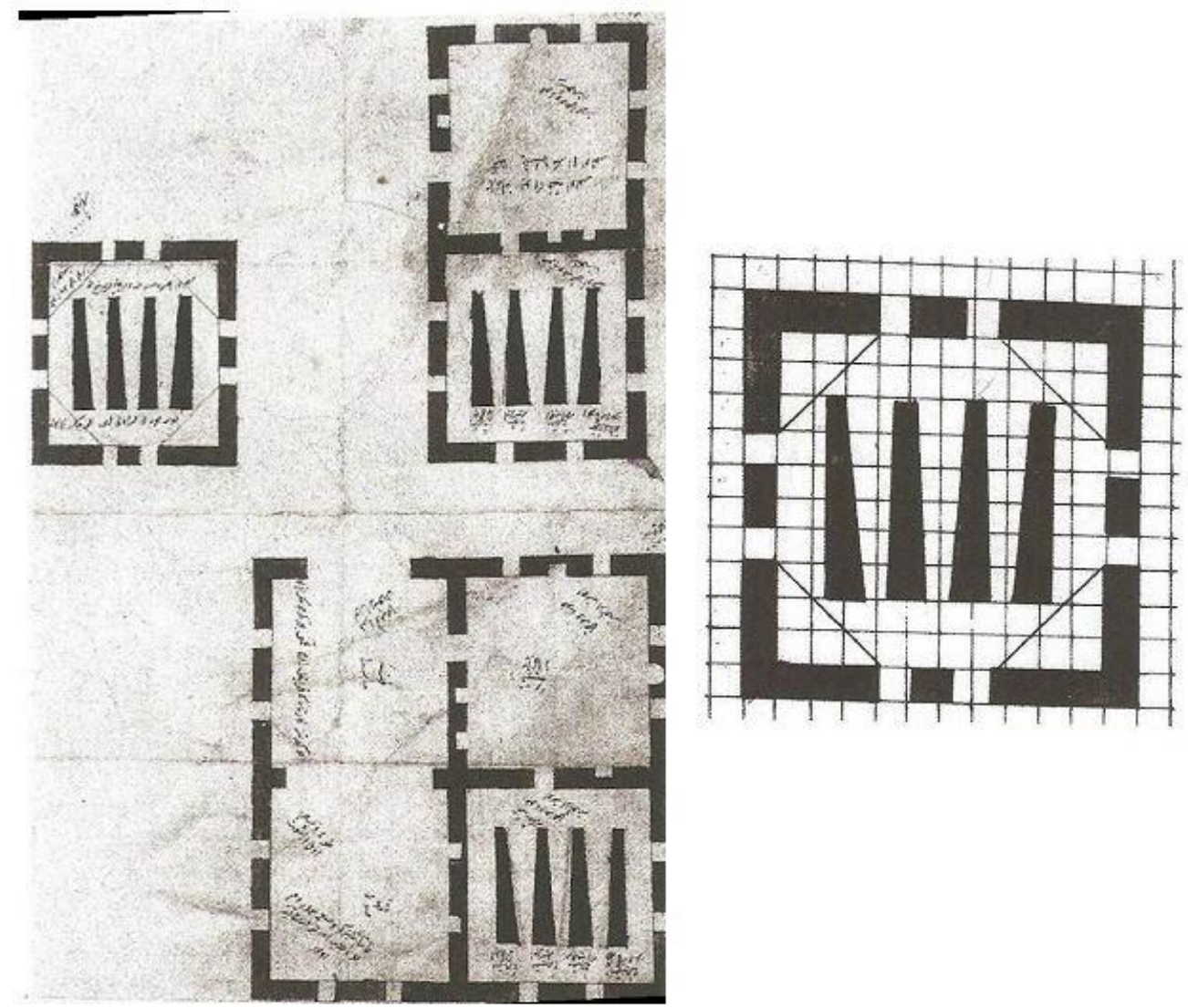

Şekil 3: Darülaceze Topkapı Sarayı Arşivi, 9495 No’da Kayıtlı Türbe Planının Üç Alternatifi (Necipoğlu, 2005; akt. Katipoğlu, 2007)

Şekil 4: Kare Tabanlı Altığı Gösteren Orijinali Üzerine Kopya Edilmiş Çizim (Necipoğlu, 2005; akt. Katipoğlu, 2007)

“Şekil 4'te bir odalı olan türbe planı incelendiğinde, plan üzerinde $0.8 \mathrm{~cm}$ 'lik her karenin 1 arşın yani 0.76 metreye denk geldiği görülmektedir. Bu planda, mevcut çizgilerinin üzerinden geçilerek belirgin biçimde ortaya çıkartılan kareli taban altlı̆̆ın kullanımının bütçe hesaplaması için Hassa Mimarlar Ocağı tarafından kullanılan pratik bir maliyet tahmin yöntemi olduğunu kanıtlamaktadır.” (Katipoğlu, 2007 akt. Yılmaz,2012).

\section{Darülaceze İnşaatıyla İlgili Belgeler}

Darülaceze inşaatıyla ilgili önemli bilgiler içeren yayınlardan biri yukarıda da bahsedilen Servet-i Fünun dergisidir. Derginin 27 Temmuz 1893 tarihli sayısı için o dönemde şantiyeye yapılan ziyaretteki izlenim ve edinilen bilgilere göre yapılar zeminden $1.5 \mathrm{~m}$ yükselmiş durumdaydı ve inşa faaliyetlerinde toplam 1200 işçi çalışmaktaydı. Bu işçilerin 800'ü inşaat alanında, 100'ü Bandırma Yapıc1 Köyü granit taş ocaklarında, 60'^ Kurbağalıdere taş ocağında, 50'si Sütlüce'de, 50'si Arnavutköy taş ocaklarında, 20'si Makriköy (Bakırköy) taş ocaklarında çalışmakta ayırca 120 işçi götürü usulüyle inșa faaliyetlerinde görev almaktaydı (Shekil 5)(Servet-i Fünun, 1893). Servet-i Fünun dergisinin verdiği bilgilerde işçilerin küçük oranlarda birden fazla taş ocağına dağıldığı görülmektedir, bunun nedeni de yine dergideki makalede verilmiştir. 


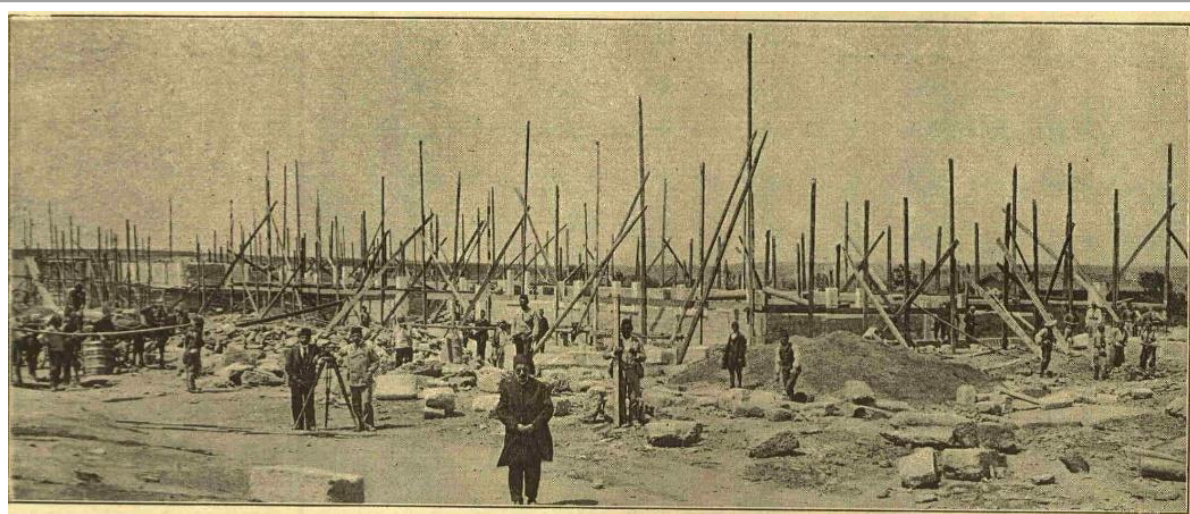

Şekil 5: Darülaceze Şantiyesinden Bir Görünüm (Servet-i Fünun, 1893)

Darülaceze ile aynı yıllarda yapımına başlanan ve Darülaceze tamamlandıktan sonra da inşası devam eden Galata Rıhtımı için gerekli olan taşların temini hususunda büyük problemler yaşanmış, rıhtım inşaatından sorumlu şirket İstanbul'daki tüm ocakları kiralamakla birlikte yeni ocaklar da açtırmıştır (Örenç, 2016; Servet-i Fünun, 1893). Bu durum Darülaceze inşaatına da yansımış ve problemin çözümü için "kontrato" (yapım şartnamesi) ve keşf-i evvelde belirtilen ancak temin edilemeyen taşlar yerine Triyeste ve Marsilya gibi şehirlerden taş ithal edilmesi dahi gündeme gelmiştir. Yapılan dayanım testleri ve fiyat karşılaştırmalarının sonucunda bunların kullanıma uygun olduğu ancak fiyatları nedeniyle kullanımlarına sınırlı miktarda izin verilebileceği değerlendirilmiştir (BOA-2, BOA-3, BOA-4, BOA-5, BOA-6, BOA-7).

\section{Darülaceze Keşf-i Sâni Defteri}

Yukarıdaki bilgilerden de anlaşılacağ gelişmeler nedeniyle ikinci bir keşif yapılması ihtiyacı ortaya çıkmaktadır. Darülaceze keşf-i sani defteri de yapılan tüm işlerin yapı yapı ve her yapının birimlerine göre sınıflandırılarak metraj çalışması ve malzeme, işçilik fiyatlarıyla gerçek yapım maliyetinin ortaya konduğu bir defterdir.

Defterin ilk maddesi zeminin tesviye edilerek temel inşaatına hazırlanma maliyetinin hesabını içermektedir. İkinci madde ise temel inşa maliyet hesabıdır. Defterdeki maddeler kompleksi oluşturan yapılar için alt maddelere ayrılmış, defterin sonunda her birimin ve hem iş kaleminin maliyetleri toplanarak genel toplam elde edilmiştir. Temel inşaatını hesaplayan maddeden anlaşıldığı üzere, temeller Kağıthane taşı ile dere kumu ve kireçten hazırlanmış örgü harcı kullanılarak inşa edilmiş̧ir (Şekil 6). Kağıthane taşı olarak belirtilen taş Servet-i Fünun dergisinde verilen bilgilere göre dergide Sütlüce taşı olarak anılan taş olmalıdır.

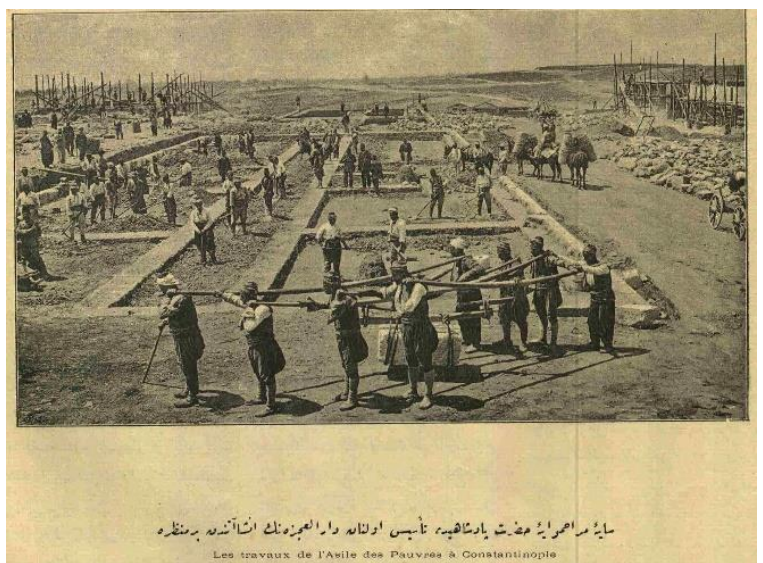

Şekil 6: Darülaceze İnşaatında Temel Aşamasını Gösteren Bir Fotoğraf (Servet-i Fünun, 1893) 


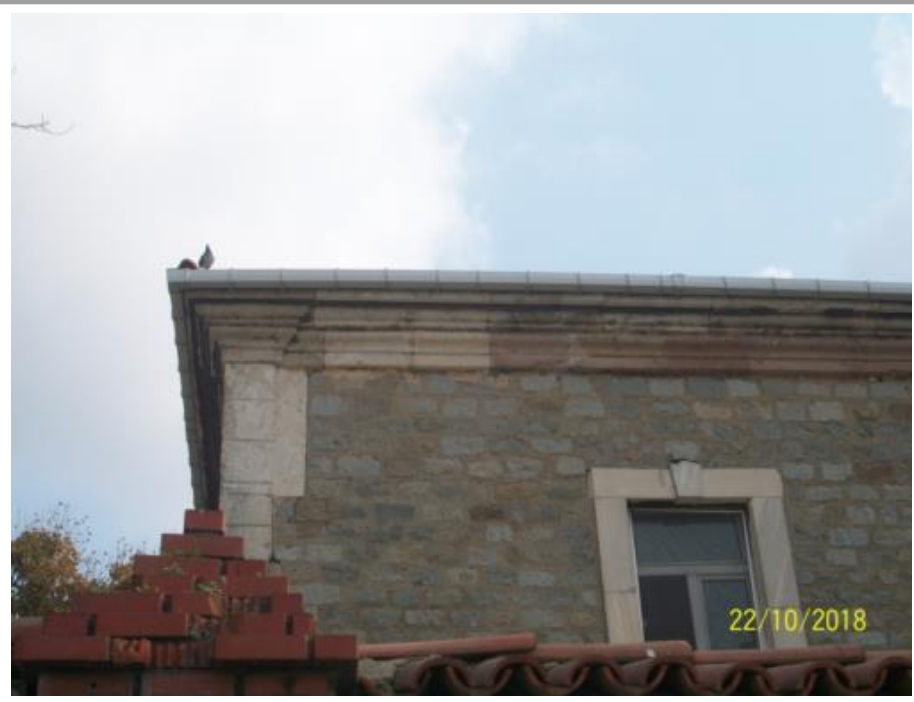

Şekil 7: Darülaceze Binalarında Tedarik Problemi Nedeniyle Farklı Taş Türlerinin Kullanımı

Defterin üçüncü maddesinde ise beden duvarları inşasının maliyeti hesaplanmaktadır. Hesap tablolarına geçmeden önce duvarın nasıl inşa edildiği detaylı bir şekilde açıklanmıştır:

"Mezkur ebniyelerin inşa olunan etraf-ı erbaa temel divarları üzerine, beş tarafi ince tarakla tesviyeli, Boğaziçi'nin sağlam tomruk taşından $40 \mathrm{~cm}$ arzında, tansifen $50 \mathrm{~cm}$ kaddında ve gövdeden çıkıntılı, kenarları pahlı, demir kenet ve çimento ile yek diğerine rabtlı olarak papuş keşideli, üzerine tedariki mümkün olabildiği derecede Boğaziçi’nin sağlam karataşından, yüzü ile etrafı tesviyeli ve kısm-1 mütebakisi mezuniyeti istihsal olunan Bandırma'nın kebir ve sagir kıt'ada granit cinsinden paket taşlar $1^{1}$ ve civar derelerinden nakil olunan kum ve kireçli harçla memzuc harici vechî divarcı sömelli ikisi bir kantarlık lama demirinden maa hancer ${ }^{2}$ iki kanat gizli hatıl bağlamalı derûn ciheti Hasköy'ün kuru kerpiç tuğlasından ikişer sıra hatıllı olmak üzere Kağıthane taşından divarlı ve köşe mahalleri $40 \mathrm{~cm}$ cesminde Makrihora ve Ayayorgi ve Belkıs taşından som kabartmalı ve kapı, pencere etrafları kezalik taşlardan yek diğerine kurşun zıvana ve kenetle rabtlı çatma söğeli iki kat binili keza taştan kafatahtalı ve derûnu kum ve kireç harçla sıvalı ve reng-i amber badanalı pencere tabanları malta füruşlu, haricen mezkur som taşlar fasl-1 müş̧terekleri Holbeck çimentosundan İngilizkâri derzli $6 \mathrm{~cm}$ cesminde çıralı hatıldan maa yağlı boya sandıklı, çerçeveli ve keza boyalı demir kanat kapılı beden divarları inşası."

Günümüz Türkçesiyle: “Adı geçen yapıların inşa edilmiş olan dört kenarlı temel duvarları üzerine, beş tarafı ince tarakla tesviyeli, Boğaziçi'nin sağlam kaba yonu taşından $40 \mathrm{~cm}$ eninde, eşit şekilde $50 \mathrm{~cm}$ boyunda ve gövdeden çıkıntılı, kenarları pahlı, demir kenet ve çimento ile bir diğerine bağlanmış olarak pabuç çıkıntılı; üzerine tedariki mümkün olabildiği derecede Boğaziçi'nin sağlam karataşından ön yüzü ile yan yüzleri tesviyeli ve geri kalan kısımlar ise kullanımı için izin alınmış olan Bandırma'nın büyük ve küçük boyutlarda kesilmiş granit cinsi paket taşları ve civar derelerden nakledilmiş kum kullanılarak hazırlanan kireç harcıyla örülmüş, dış yüzü duvarcı sömelli; iki adedi 44 okkalık $(56,449 \mathrm{~kg})$ lama demirinden, kılıçla iki kanat gizli hatıl bağlamalı, iç tarafı Hasköy'de üretilen kuru kerpiç tuğlasından iki sıra hatıllı olmak üzere, Kağıthane taşından duvarlı ve köşe kısımları $40 \mathrm{~cm}$ genişliğinde Makriköy (Bakırköy), Ayayorgi ve Belkıs (Belkıs Köyü, Bandırma) taşından som kabartmalı ve kapı, pencere söve ve lentoları aynı taşlardan bir diğerine kurşun zıvana ve kenetle bağlı, çatma söveli, iki kat binili, aynı taştan saçak silmeli ve içi yüzeyi kum kullanılarak hazırlanmış olan kireç harcıyla sıvalı, amber

\footnotetext{
${ }^{1}$ Paket taşı: Mevâdd-1 volkaniyeden mütehassıl bir nev'i sert taş olub dört köşe yontularak kaldırım imâlinde kullanılır. (Arseven, 2017)

${ }^{2}$ Hancer: Bağlamaların ucunu rabt içün müsta'mel temurden mâmul küçük kılınç. (Arseven, 2017)
} 
rengi badanalı, pencere tabanları malta füruşlu, dış yüzeyi adı geçen som taşlar ile derzleri Holbeck çimentosuyla İngilizkâri usulünde (Şekil 8) yapılmış, $6 \mathrm{~cm}$ genişliğinde çıralı hatıldan yağlı boyalı sandıklı, çerçeveli ve aynı şekilde boyalı demir kanat kapılı beden duvarları inşası"

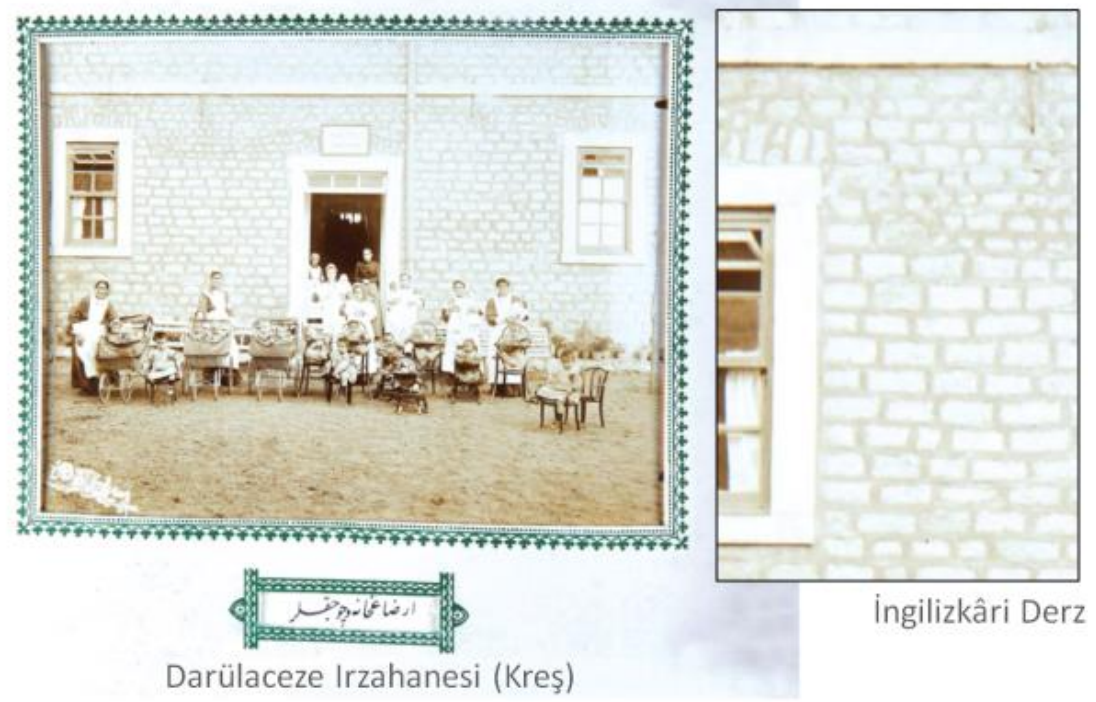

Şekil 8: Darülaceze Binalarının Beden Duvarlarına Bir Örnek ve Bir Detay Fotoğrafı (Darülaceze Albümü, 2013)

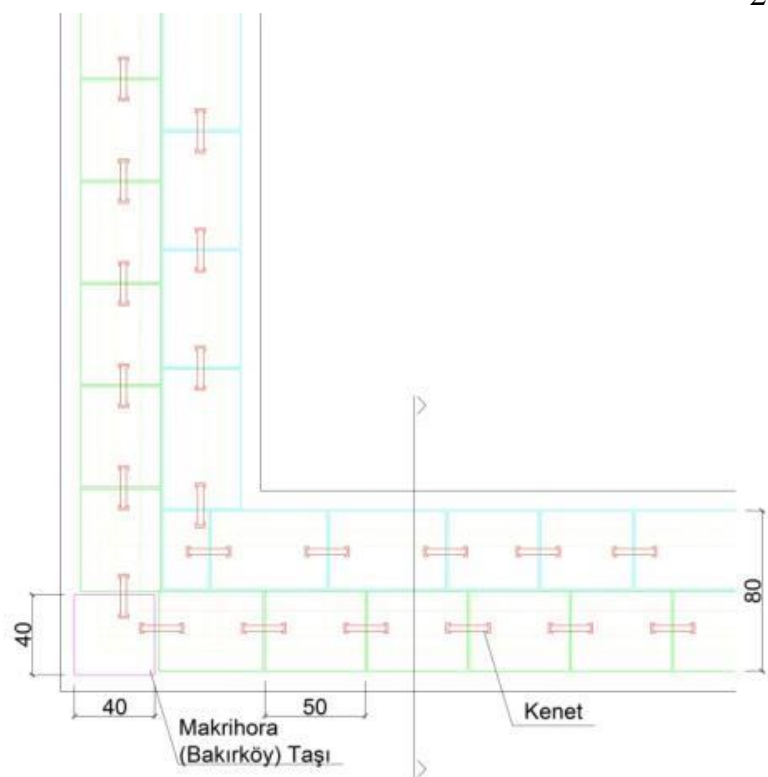

PLAN

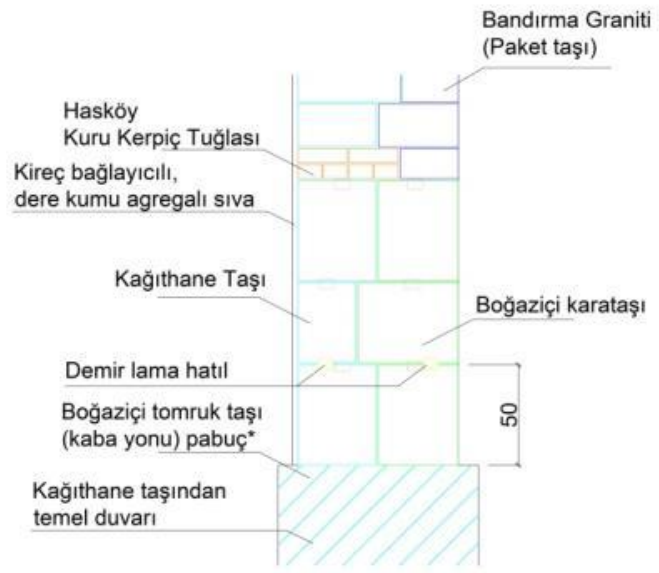

Şekil 9: Defterde verilen bilgilere göre hazırlanan beden duvarı plan ve kesiti

Defterde kullanılan bu detaylı tanımlar, günümüzde artık kullanılmayan yapım tekniği adlarının anlamlarının tespit edilmesine olanak sağlamaktadır (Şekil 8). Bu durum defterdeki malzeme isimleri veya harç içerikleri için de geçerlidir. Örnek verilecek olursa:

- Islak hacim zeminlerinde: Çini dökme taklidi, yerli çimentodan, çimento paket döşemesi ${ }^{3}$

${ }^{3}$ Çini dökme taklidi, yerli çimentodan, çimento paket döşemesi: Karosiman, terrazzo karo 
- Bodrum kat beden duvarlarında: Ayayorgi, Makrihora ve Triyeste taşından pencere etrafları

- Bodrum kat beden duvarlarında: Maden kömürü tozlu ve kireçli harç

- Defterde geçen bazı yapı elemanı ve malzeme isimleri: Horasanlı halisi harç, kuru kerpiç tuğlası, fabrika tuğlası, üç delikli tuğla, on iki delikli tuğla, çarşu tuğlası, Malta? Döşeme, samanlı çamur sıva, Frenk mermeri, İtalya mermeri, Tolos ${ }^{4}$, lüleci çamuru ${ }^{5}$, lökün ${ }^{6}$

Defterdeki detaylı tanımların sağladığı bir diğer avantaj ise yapım tekniğini basitçe açılayarak, detay çizimlerinin yapılmasına dahi imkân verecek şekilde bilgi vermesidir.

Örnek-1: Tavanlar (Şekil 10,11); “18 santim ...sinde putrel demirinden 60 santimde bir kirişli ve 1 metro 80 santimde bir tarafın başları 16 kıyyelik lama demirinden maşa ve hancerle rabtlı olarak kirişli, binileri üç delikli tuğla; kum ve çimentolu harçla tonoz ... tahtı kum ve İngiliz çimentosu harçla sıva ve matlub rekte badanalı üzeri 10 santim ...sinde 5 santim cesminde Filyos ... latasından çiğli ve bazan çıralı ...sinden ve mütebakisi dahi kalastan 3 santim cesminde lambalı kaplı üst kat döşeme tavan inşası"

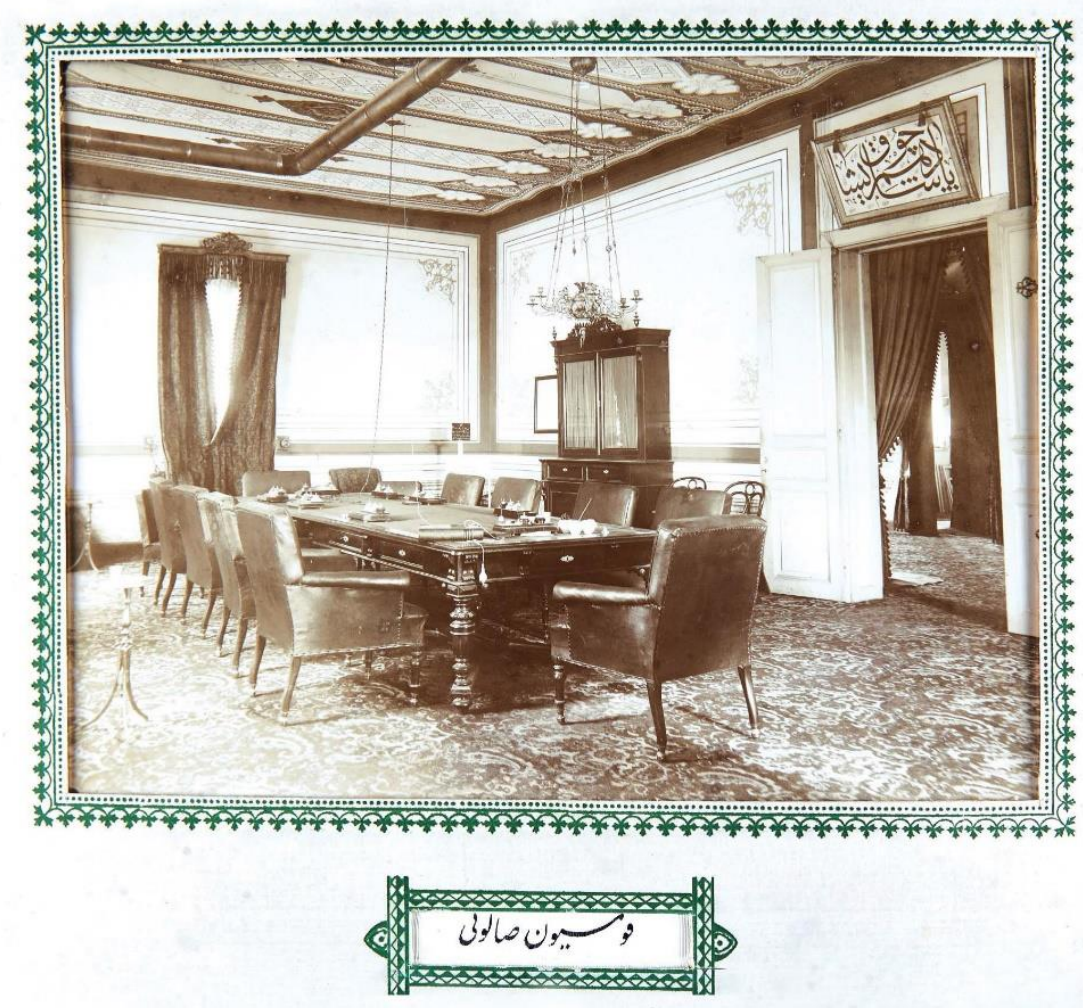

Şekil 10: Darülaceze komisyon salonu ve tavanı (Darülaceze Albümü, 2013)

\footnotetext{
${ }^{4}$ Tolos: Tonoz

${ }^{5}$ Lüleci çamuru: Lülecilerin kullandıkları özlü ve süzülmüş kızıl balçık. (Sami, 2015)

${ }^{6}$ Lökün: Kireç ile zeytun yağı veya bezir yağından dökülerek yapılan bir nev' macun ki su boruların etrafi sararak suyun akmasına mani olmakda müsta'meldir. (Arseven, 2017)
} 

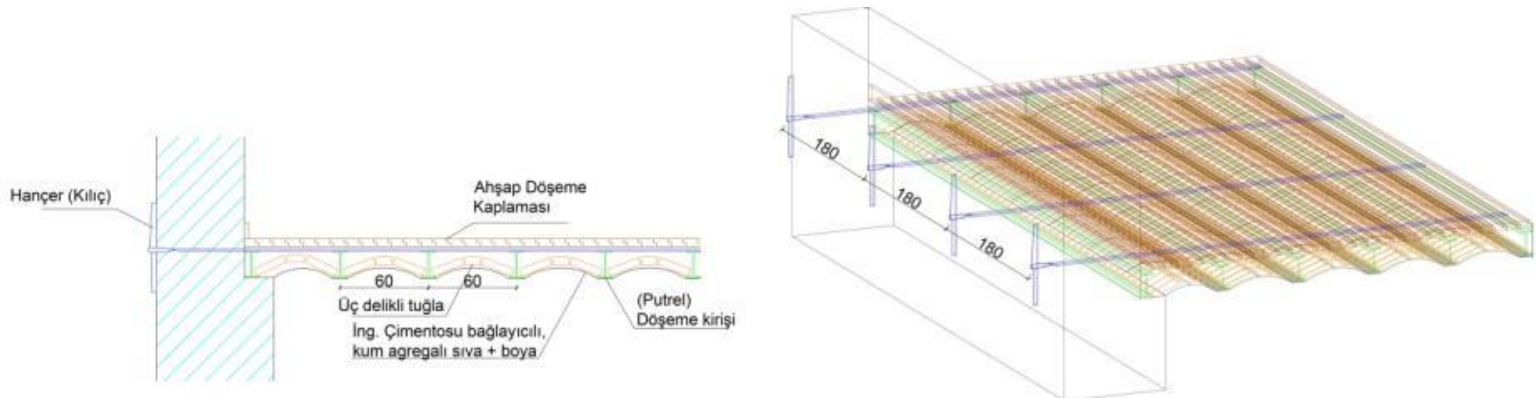

KESIT

KISMI PERSPEKTIF

Şekil 11: Defterde verilen bilgilere göre hazırlanan volta döşeme kesiti ve kısmi perspektifi

Örnek-2: Çamaşırhane kazanları (Şekil 12); "Cedid taş halisi harçlı, üzeri ateş tuğlası, lüleci çamuru harçlı taban döşemeli, etraf-1 harici kerpiç tuğlası, delikli ateş tuğlası gömlekli çamaşırhane kazanları"

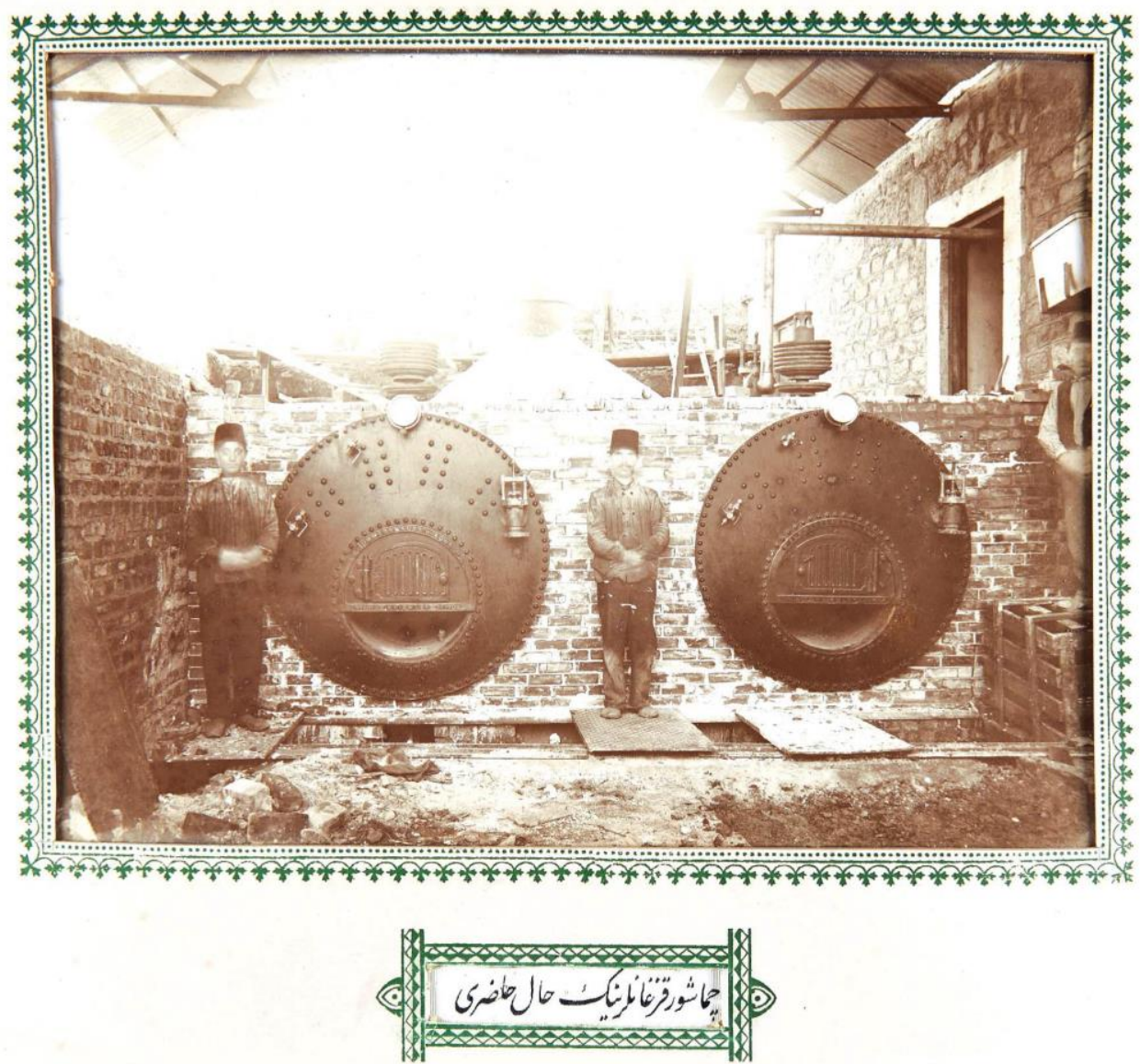

Şekil 12: Darülaceze çamaşırhane kazanları (Darülaceze Albümü, 2013)

\section{Turkish Studies - Historical Analysis}

Volume 14 Issue 3, 2019 


\section{Değerlendirme}

Darülaceze ve diğer yapılar için hazırlanmış olan keşf-i sani defterleri Osmanlı dönemi mimarlık pratiklerinin anlaşılması ve doğru değerlendirilmesi adına, özellikle malzeme kullanımı, yapım detayları ve yapı terminolojisi konularında önemli katkılar sağlayabilecek belgelerdir. Bunun yanında, koruma ve restorasyon çalışmalarında da ihtiyaç duyulan restitüsyon ve malzeme türü / içeriği bilgilerinin elde edilmesine keşf-i sani defterlerinin katk1 sağlayabileceği göz önünde bulundurularak yapılacak araştırmalara (literatür, laboratuvar vs.) çalışma konusu olarak dahil edilmelerinin yararlı olacağı düşünülmektedir

Bu çalışmada öncelikli olarak Darülaceze keşf-i sâni defterinin tanıtılması amaçlanmıştır. Defterde adı geçen doğal taş türlerinin bilimsel adlarının ve özelliklerinin tespiti, harçların içerikleriyle teknik özelliklerinin değerlendirilmesi, terminolojinin detaylı bir şekilde saptanması gibi çalışmalar da araştırılmaya açık konulardır.

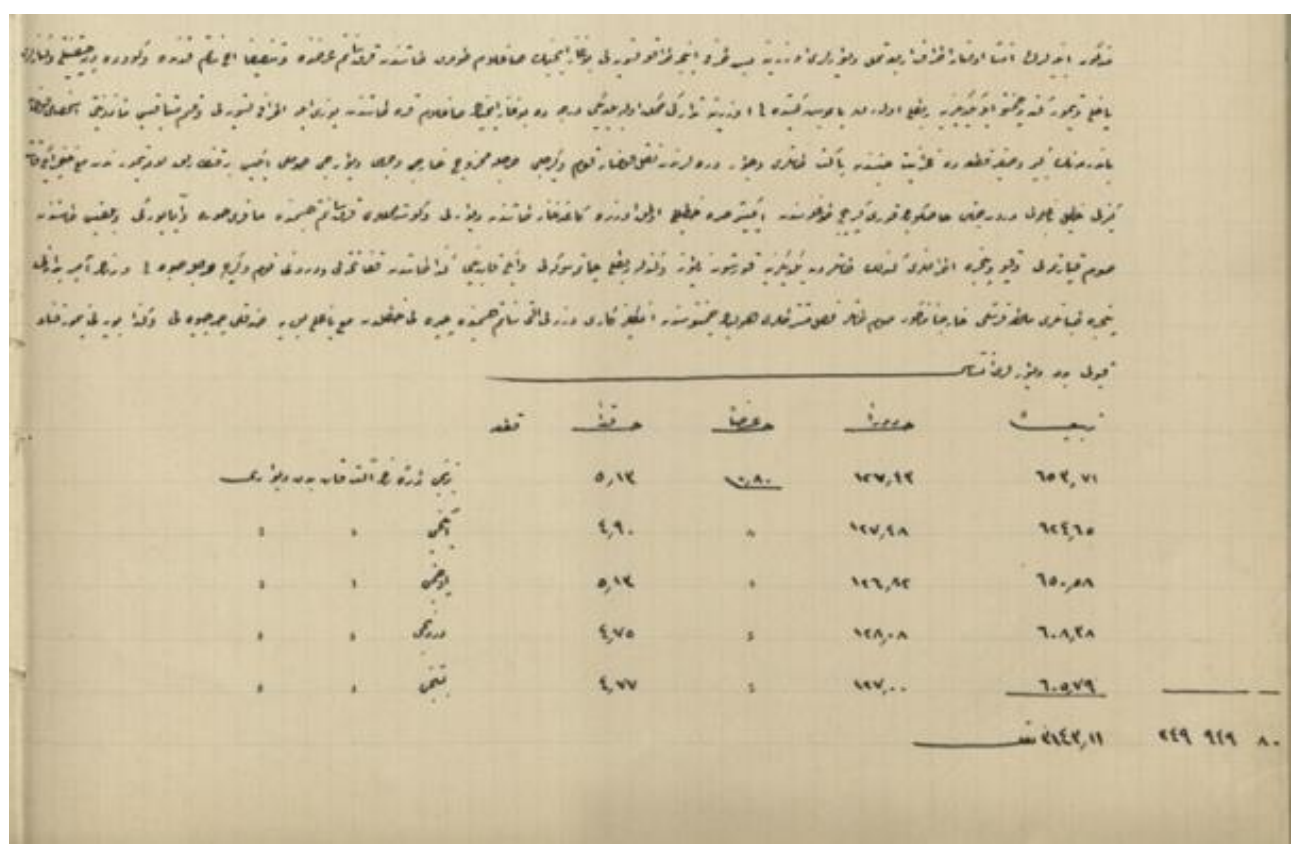

Şekil 13: Darülaceze Beden Duvarlarının Yapımını Tarif Eden ve Hesaplamaları Gösteren Kısım

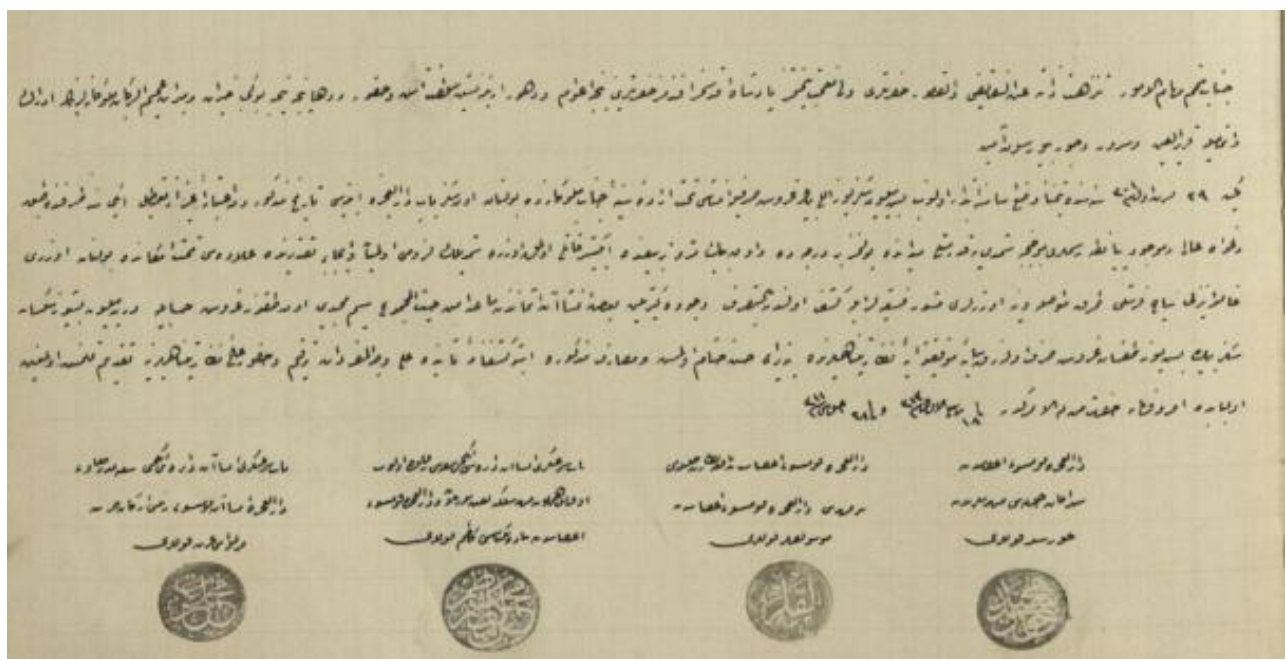

Şekil 14: Darülaceze Keşf-i Sani Defterinin Son Bölümü: “... pianta resimleri mucibince, iki sene zarfinda 4.588.590 kuruş sarf edilerek vücuda getirilen 18 bab Darülaceze ebniyesi...’ 


\section{KAYNAKÇA}

Arseven, C.E. (2017). Osmanlı Dönemi Mimarlık Sözlüğü - Istılahat-ı Mi'mariyye, Çeviren: Şeyda Alpay, Kaknüs Yayınları, İstanbul.

Darülaceze (1906). Ehasin-i Müessesat-ı Hayariyye-i Hilafetpenahi'den Darülaceze, Mihran Matbaası, İstanbul.

Darülaceze Albümü (2013). Aile ve Sosyal Politikalar Bakanlığı, İstanbul.

Hızlı, M. (1991). Bursa Mahkeme Sicillerine Göre XIV - XVI Yüzyıllarda Bursa Medreseleri, Uludă̆ Üni., SBE, Yayımlanmamış Doktora Tezi, Bursa.

Katiopoğlu, C. (2007). Osmanlı İmparatorluğu'ndaki Yapı Pratiği İçinde Mimari Çizimin Yeri, Yeni İpek Yolu Dergisi, Konya Ticaret Odas1, 447-452, Özel Say1: Aralık, 2007.

Necipoğlu, G. (2005). The Age of Sinan: Architectural Culture in the Ottoman Empire, Princeton Uni. Press, Princeton and Oxford.

Örenç, A.F. (2016). Modern İstanbul Limanı'nın İnşası Sürecinde Galata ve Eminönü Semtlerinde Kentsel Değişim, Uluslararası Osmanlı İstanbulu Sempozyuтu 4, İstanbul.

Özen, İ. (2001). II. Meşrutiyet'e Kadar Islahhaneler ve Darülaceze, Ankara Üni. SBE Tarih (Yakınçağ) ABD, Yayımlanmamış Yüksek Lisans Tezi, Ankara.

Sami, Ş. (2015). Kamus-i Türki, TDK Yayınları, Ankara.

Servet-i Fünun Dergisi (1893). No:124, İstanbul, 15 Temmuz 1309.

Ünsal, B. (1963). Topkapı Sarayı Arşivinde Bulunan Mimari Planlar Üzerine, Türk Sanatı Tarihi Araştırma ve İncelemeleri, 168-197, İstanbul.

Yılmaz, İ. (2012). Osmanlı Dönemi Mimarlık Eserleri Restorasyon İnsaat Maliyetlerinin Yapay Zeka Yöntemleri ile Tahmini, İstanbul Kültür Üni. FBE İnşaat Müh. ABD, Yayımlanmamış Doktora Tezi, İstanbul.

BOA-1: Darülaceze Keşf-i Sani Defteri, Yer: Y.EE.d. , 746, Tarih: 18.Ra.1313

BOA-2: Darülaceze ebniyesi için gerekli taşın Makriköy taş ocaklarından temin edilmesi, Yer: A. \}MKT.MHM. / 703 - 5 - 0, Tarih: H-28-02-1311

BOA-3: Darülaceze'nin inşa şartlarını bildiren keşif defterinin Dahiliye Nezareti'nce takdimi, Yer: Y..MTV. / 65 - 69 - 0, Tarih: H-18-01-1310

BOA-4: Darülaceze binasının gövde duvarlarında kullanılacak taşlar ve bunların tedariki, Yer : DH.MKT. / 3 - 13 - 0, Tarih: H-29-08-1310

BOA-5: Hastahane hamam ve acezehane gibi Darülaceze binaları inşaatının tamamlanabilmesi için Makriköyü Taş ocaklarından temin edilemeyen taşların Triyeste ve Marsilya taşlarından imali hususunda gereğinin yapılması Yer: DH.MKT. / 124 - 4 - 0, Tarih: H-18-02-1311

BOA-6: Darülaceze binalarından yapılmakta olan bir hastahane, hamam ve üç eczahanede hasıl olan mecburiyete binaen Makriköy taşı yerine Marsilya ve Triyeste taşı kullanılmasını havi talep üzerine mezkur taşlar hakkında tahkikat icra olunması. Yer: MV. / $76-11-0$, Tarih: H-2202-1311

BOA-7: Darülaceze binalarından yapılmakta olan bir hastahane bir hamam ve üç acezehanenin yapımında kontrato gereği Makriköyü taşı kullanılması. Yer: MV. / 76 - 64 - 0, Tarih: H-1003-1311 